\section{The geology of Australia}

\section{By David Johnson}

Cambridge University Press, Cambridge, New York, Melbourne, Madrid and Cape Town, 2004, xii + 276 pp. A \$150.00, ISBN 0521841216 (hbk); A\$69.95, ISBN 0521601002 (pbk).

I first happened to see this book on the counter at a local bookshop, noted the price, and commented to the bookseller that at $\$ 150$ I would not be thinking of buying it, though I liked the look of the book. His reply was "Well, it's an academic book, and they are very expensive these days". How true! Fortunately, I later discovered the paperback edition at less than half the price of the hardback; so I bought it and am glad that I did.

David Johnson, who works at James Cook University, North Queensland, has had wide experience as a geologist in Australia, and has now produced the first general account of the geology of the continent since the semi-popular works of Charles Laseron (The Face of Australia, £1 8s 6d, 244 pp., 1952, and Ancient Australia, £1 5s, 210 pp., 1954), which succeeded the more technical posthumous work of Edgeworth David (edited and supplemented by W.R. Browne): The Geology of the Commonwealth of Australia (1950).

Johnson's book is in some ways similar in scope and intent to the volumes by Laseron in that it offers a general coverage, suited to the interested non-professional geologist. (Contrary to the opinion of the bookseller, it isn't really an 'academic' book.) But publishing has changed a good deal in the intervening half-century. Laseron had a number of nice black-and-white photographs and some simple line-diagrams, whereas Johnson's book has beautiful colour photographs or clear computer-drawn diagrams on almost every page, and is made easy to navigate by the use of numerous headings and sub-headings. And each chapter is conveniently and neatly summarized at its conclusion. In keeping with the dictates of modern publishers, who try not to frighten off non-academic readers (sic!) by footnotes, there are no such - so useful! - deterrents, but each chapter has a good accompanying reference list.

Johnson plunges in with a clear account of some of the major features of modern geotheory: radiometric dating; plate tectonics and ideas about the Earth's interior; minerals; rock types; metamorphism; regoliths, geomorphology; the form of the continental margins; the Earth's origin and its subsequent thermal history; the supercontinents Rodinia and Gondwana. Thence, through successive chapters, he outlines a geological history of the globe - focused on Australia, of course (though Australia didn't exist as a recognizable entity when it was,

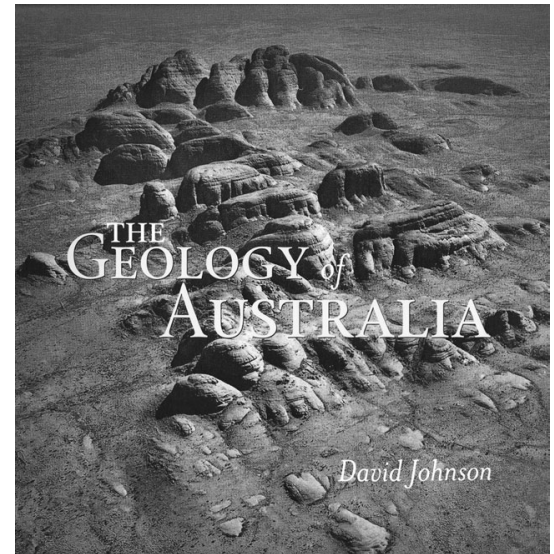

e.g., part of Gondwana). He goes way back into the Precambrian and discusses questions such as our continent's three ancient cratons, the emergence of life, the banded iron formations, the emplacement of ore bodies, Australia's volcanism and its orogenies, and so on. Palaeontological concepts are introduced as this history is unfolded. Attention is given to such matters as the separation of Australia from Antarctica, climatic changes (especially ancient glaciations), changes in sea levels, coastal landforms and reefs and deserts. Even political matters get a look in, with mention of the UN Convention of the Law of the Sea and the Australian Exclusive Economic Zone. (Here there is a problem, as Australia's continental shelf margin is situated much closer to poor little East Timor than to the big continent. So if the political boundary is set half way between the two countries East Timor gets much more oil. If the boundary is defined by the edge of Australia's continental shelf, the little new country gets much less oil than the big old one. The issue is not yet resolved at the time of writing.)

There is a substantial section on meteorites and impact craters, and attention is also given to topical issues such as tsunamis (to which Australia is vulnerable, even though it is seismically stable). Milankovic cycles are mentioned, but contrary to some current thinking Johnson does not appear to accept that they explain all recent climatic changes satisfactorily, though he certainly acknowledges the role of astronomical factors in global climatic changes, pointing out that there are climatic cycles as well as tectonic cycles.

In general, the diagrams are excellent and one showing the aggregation and dispersal of supercontinents over the last two billion years (p. 256) is particularly helpful, as is the coloured vertical section (p. viii) showing the relation of the chapter heads to the episodes of glaciation, volcanism, and marine inundation in the (wandering) region of Australia. Reference is made in the text to some evidence for Cretaceous glaciation in South Australia, surprising though that might be in view of the supposed high global temperatures and sea levels at that Period.
The Australian Permian coal deposits are interpreted as having been formed from peat accumulations on coastal plains under coldclimate conditions. Other special 'Australian' problems discussed briefly are the controversy over the extinction of the Australian megafauna in the late Pleistocene (was it due to hunting by humans or climatic changes?); the Ediacara fauna; the wonderful stromatolites at Shark Bay, Western Australia; the formation of Ayer's rock (Uluru), etc. More detailed attention is given to the Great Barrier Reef-near where Johnson now works.

Naturally, there is discussion of the special, generally rather flat, and definitely arid, landscape of much of Australia. Why are the soils mostly poor? Unfortunately, we missed out on having a good glacial cover and churning of the subsoil during the Pleistocene. Australia is not Europe (though the early settlers tried to make it so, often with disastrous results). The wealth and poverty of Australia are both linked to its geological and geographical histories; and Europeans are still not fully 'at home' here. We do not have a sustainable way of life.

The Geology of Australia is to be warmly welcomed as a fine exposition of an immensely complex story, and although the presentation of that story is somewhat disjointed it is hard to see how it could have been otherwise, given that the author has chosen not to give a Period-by-Period exposition of the geological history of the continent but involves himself in much broader theory as his exposition proceeds.

I anticipate that the book (its paperback edition!) will sell well, and deservedly so, and will provide material of value to teachers both at secondary and tertiary levels. Interested Australians will be able to get a fine introduction to geology from this book, and overseas geologists will get a clear introductory account of the continent's geology. However, academics will mostly be unable to afford the hard-cover edition!

\section{David Oldroyd}

School of History and Philosophy of Science

University of New South Wales

Sydney NSW 2052

AUSTRALIA

d.oldroyd@unsw.edu.au 


\section{Glaciers}

\section{By Michael Hambrey and Jürg Alean}

Cambridge University Press, 2nd Edition, 2005, 376 pp., 35.00 Euro (US\$60.00) ISBN 0521828082

This book is the second and expanded volume of Glaciers, the first published in 1992. The second edition contains four more chapters and the whole text has been fully revised. The book is divided into sixteen chapters logically progressing from an outline of ice on Earth through various chapters detailing the nature of glaciers and their environments supported by an array of magnificent colour photographs and examples.

The first chapter 'Earth, the icy planet' details the extent of glaciers that currently exist as well as the history of ice on Earth. This chapter concisely demonstrates the importance of glaciers to the shaping of the Earth's surface and the response of glaciers to global climate change. It also highlights the importance of glaciers as a water resource for man in modern times, their dangers, and their future in response to increasing global temperatures, setting the scene for the following chapters.

Chapter 2 'The glacier family' summarises the main glacier classifications. The authors describe the two main criteria: their topographic and temperature settings. The chapter is superbly illustrated with photographs of the full range of topographic glacier types including ice sheets, ice caps, ice fields, piedmont glaciers, valley glaciers and cirque glaciers as well as a photograph of a polythermal glacier in Antarctica. Thus, in only a few pages the glacier family is introduced clearly and effectively without subjecting the reader to unnecessary classificatory description.

Chapters 3 and 4 deal with related issues, namely the 'Birth, growth and decay' of glaciers and 'Fluctuating glaciers' respectively. In Chapter 3, the concept of mass balance is introduced as well as its measurement in the field. This leads on to Chapter 4, which documents glacier fluctuation with particular focus on mountain glaciers of the European Alps and tidewater glaciers in Alaska. A short section is also devoted to tropical regions and highlights the major recession experienced in these areas, with $82 \%$ of the Kilimanjaro ice cap lost since 1912. In addition, human-induced glacier recession is noted, in particular that caused by hydroelectric schemes and global warming.

As with the previous two chapters, Chapters 5 and 6 are related. Chapter 5 deals with 'Ice on the move' outlining the mechanisms of glacier flow and subsequent structures such as ogives and crevasses. Surging glaciers are given particular attention, accompanied by several photographs from

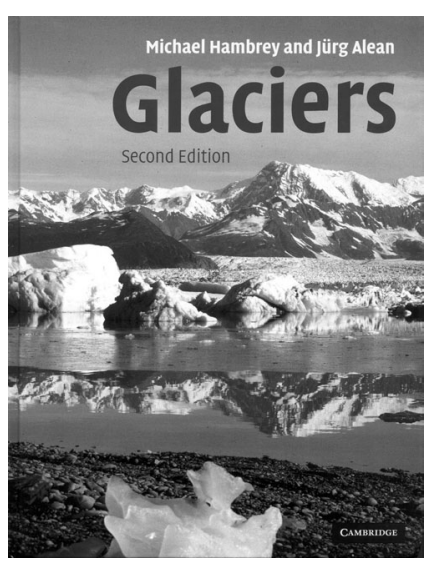

around the Arctic region. Chapter 6, 'Natures conveyor' describes the effects of glacier flow in producing debris, on, within and below ice, and illustrates the different properties of debris conveyed in different parts of the glacier.

Chapter 7 describes the inherent relationship between ice and water and the effects of melting on the glacier system. The impacts can be dramatic and have major implications for humans. At the most spectacular scale, flooding can result from subglacial volcanic activity-termed 'jökulhaup' in Iceland. In particular, the authors highlight the direct of relevance of glaciers and water on human populations, a point revisited later in Chapters 12 and 13.

Antarctica is the subject of Chapter 8 . Here, Hambrey and Alean describe the characteristics of ice masses on the Earth's most glacierized continent. They provide a stimulating synthesis of ice in this key region and provide interesting discussion regarding recent and future change.

Chapter 9 describes the interaction between glaciers and volcanoes and examines glaciers associated with volcanic activity in the 'Ring of Fire', on the 'Mid Atlantic Ridge' and in Antarctica. Volcanoes can have a devastating impact on glacier melting, dovetailing with the discussion of ice and water in Chapter 7.

Chapter 10 describes longer term processes of glacial erosion and deposition and associated legacy of landforms and sediments. This legacy is illustrated in this chapter by excellent photographs of landscapes, landforms and sediments produced by glaciation from around the world.

Chapter 11 examines glacial environments as a habitat for wildlife. Even in such harsh conditions, glaciers and their surroundings are home to numerous species of fauna and flora, once again superbly illustrated here by colour photographs.

Chapters 12 to Fourteen focus on the direct relevance of glaciers to humans. Chapter 12, 'Benefits of glaciers' outlines the use of glacier meltwater for irrigation and energy supply and glaciers themselves as objects of tourist interest; from skiing to mere observation. The authors also highlight the economic potential of glacial deposits, as both an aggregate and aquifer resource, as well as the value of glaciers as an educational resource. Chapter 13, 'Glacier hazards' provides an interesting review of the perils of glaciers supported by examples of glacier-related catastrophes from across the globe. After reading previous chapter the last thing you would recommend is 'living and travelling on glaciers'. However, this is precisely the topic of Chapter 14. This chapter provides interesting insight into the practicalities of glacier research illustrated by numerous photographs of activity on glaciers in both polar regions.

Chapter 15 examines the Earth's glacial record. This overlaps somewhat with Chapter 10, although outlines in more detail the record preserved in the landforms and sediments including ancient glaciations during the Archaean and Proterozoic as well during the Cenozoic. For the latter, Hambrey and Alean detail the evidence for glaciation during the Quaternary Period in the deep-sea, continental shelf, onshore and ice core records and examine the pattern and causes of ice ages.

The future of glaciers is considered in the final chapter, Chapter 16. The importance of glaciers to human civilisation is stressed here with emphasis on the effects of future global warming, glacier melting and sea level changes. Hambrey and Alean also consider the effects of glacier retreat on water resources for human communities and the increased potential for glacier disasters, such as flooding and landslides. They end by speculating on the potential for a future return to an ice age and note that 'in a few thousand years ice sheets may once again extend towards mid-latitudes, across the greater part of northwest Europe, North America and elsewhere'.

This book would be of interest to all those interested in glaciers and would especially appeal to the general reader. The book is also a valuable resource as an introductory text to accompany more detailed textbooks on glaciers and glaciation for undergraduate courses. Even for seasoned researchers, the book would be of interest, even if only for its superb colour photographs - a feature of almost every page. In conclusion, the book probably represents one of the most interesting, easy-to-read and well-illustrated available on the subject of glaciers and is therefore recommended to all readers with an interest, at any level, in glaciers and glaciation.

\section{Dr. Philip Hughes} Geography

School of Environment and Development

The University of Manchester

Manchester M13 9PL

UNITED KINGDOM 


\section{Time series analysis and inverse theory for geophysicists}

\section{By David Gubbins}

Cambridge University Press, 2004, paperback, 255pages, 51 illustrations, ISBN $0521525691, £ 27.95$ (US\$50.00); hardback, ISDN $0521819652, £ 70.00$ (US\$100.00)

Thanks to the advances in geophysical measurement technologies, most geophysical data are now recorded in digital form. But to extract the 'Earth's nature' from observed data, it is necessary to apply the signal-processing method to the time-series data, seismograms and geomagnetic records being the most common. The processing of time-series data is one of the major subjects of this book. By the processing of time series data, numerical values such as travel-times are obtained. The first stage of data analysis is forward modeling, but the more advanced step is the inversion method. This is the second subject of this book.

Avoiding the use of heavy mathematics, the book uses the discrete Fourier transform, rather than the continuous treatment of the Fourier integral, given in Appendices. Although the author makes a considerable effort to describe the data processing and inversion by simple means, it is likely to be still too difficult for most field geologists. For this reason, this review may be also difficult to understand for many readers. Nevertheless, I shall try to explain the essence of the text.

This book is divided into twelve chapters, with seven appendices, four pages of references, and an index. It is divided into an Introduction (Chapter 1) and three parts. The first part describes data processing; the second part explains the technique of inversion; and the last part gives examples of its applications. Each chapter has exercises. The Introduction introduces the 'nature' of digital processing.

Part 1 is divided into four chapters. Chapter 2 provides the mathematical preliminaries needed to describe the fundamentals of digital processing such as the z-transform and the discrete Fourier transform (DFT). Chapter 3 describes the practical estimation of spectra. In the practical treatment of spectral analysis, there are some important points: aliasing caused by limited sampling interval; spectral leakage from the shape of the time window; and tapering for minimizing the side-lobes. Three examples of spectral analyses are given, using real dataset. Chapter 4 is processing of time sequences. Filtering is the most basic procedure. Several different treatments in filtering principle are presented. Minimum phase filtering does not violate the causality of time sequences. The

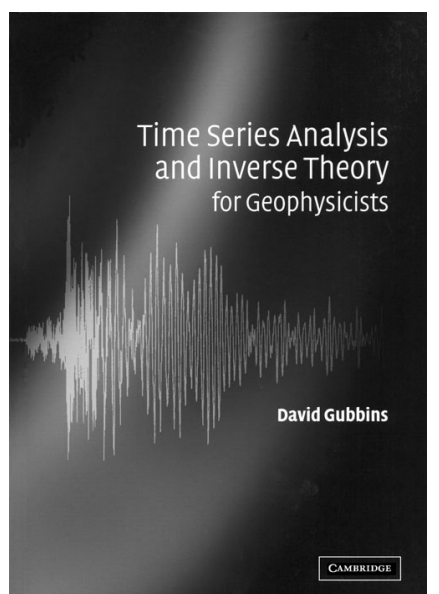

correlation method is used to find relations among data sets. The 'deconvolution' method is used to eliminate the multiples or reverberations through travel paths. This is the most basic treatment in seismic prospecting. The deconvolution can be done in the frequency domain. Appropriate computer exercises are provided for Butterworth filtering, the filtering of broadband seismomograms, correlation, and 'deconvolution'. Chapter 5 discusses cases of two-dimensional data. Here, the 2D Fourier transform is introduced, which can be applied to 2D filtering and travelling wave cases.

Part 2 (four chapters) discusses the inversion method, the theory of which is described as simply as possible. There are two distinct cases in inversion: linear inversion and non-linear. Even with insufficient data-sets relative to the unknown variables, solutions of inversion can be obtained. Chapter 6 treats linear inversion. The target problem can be assumed as a set of linear equations. If the number of equations to describe data is more than the number of unknowns, the solution is obtained by minimizing sum of the squares of the errors: the least-square method. Data should be weighted according to their quality. The unknowns may also have some estimated bounds, which are treated as a covariance matrix of the model space. The statistical treatment gives an error ellipsoid. Robust methods to eliminate 'outliers' (data obtained by mistakes) from the dataset are also described. Chapter 7 is the case of there being fewer independent equations than unknowns. Now the normal equation of the least-squares is re-written by the use of a covariance matrix and weight (damping parameter). Solutions are obtained by minimizing the modified normal equation. The case of non-linear problems is described in Chapter 8. A grid search, Monte Carlo and linearization are general methods used to solve the non-linear problems. A typical example for the non-linear problem is the determination of hypocenters. If the problem is assumed to be a quasi-linear case, iteration can be applied. Chapter 9 treats the continuous inverse problem and the inversion of continuous functions is estimated.
Part 3 describes the application of timeseries analysis and inversion theory in geophysics. It is divided into three chapters. Chapter 10 is the case of Fourier analysis as an inverse problem. In seismic travel-time analysis, seismic tomography is most important (Chapter 11). Beam-forming methods enhance the signals' quality. Using such enhanced seismic waves, seismic tomography using the travel-time inversion method can be performed. The so-called ACH (Aki, Christofferson, and Husebye) method is described as the standard. (Here I should like to express my sorrow for the recent loss of Prof. Aki, who initiated travel-time inversion.) The description of tomography is quite simple, partly because the essential part is given in the inversion and partly because earlier literature already describes numerous examples of travel-time tomography. The combination of hypocentre determination and inversion of earth structure is simultaneously inversed. The last chapter describes applications to geomagnetism, and has a short introduction for the beginners in geomagnetics. First, geomagnetism problems are solved by the forward method. Second, the inversion method is applied. In the linearization for the non-linear problems, the uniqueness of the solution is important. To increase the accuracy of the estimation, the introduction of damping is necessary. Averaging of spatially-distributed data may increases the accuracy of solution, but the precision in space may decrease. This is called 'trade-off'. For more global-scale studies, the fluid motion in the Earth's core is discussed.

In order to fill the gap between discrete and continuous treatments, seven appendices are given: Fourier series; Fourier integral transform; Shannon sampling theorem; linear algebra; vector space and function space; and Lagrange multipliers. The last appendix gives files for computer programming exercises and real-world applications.

This book is written as a textbook for undergraduate and graduate students doing a geophysics major. In my judgment, it is one of the outstanding textbooks for introducing the mathematical background not only to students but also to geophysicists in the early years of their careers. This book will also be most useful as a textbook for students and junior scientists working on time-series data in other disciplines. The contents of this book may be too difficult for field geologists as mentioned earlier, but it may be a worthwhile challenge to such persons wishing to have a general appreciation of the subject.

\section{Prof. Junzo Kasahara}

Tono Geoscience Center,

1-63 Yamonouchi, Akeyo-cho,

Mizunam, Gifu, 509-6132.

JAPAN 


\section{Volcanoes and the environment}

\section{Edited by Joan Marti, Gerald G. J. Ernst}

Cambridge University Press, 2005, 471pp., ISBN 0521592542 (hardback), $£ 50.00$ (US\$90.00)

The cover shows a great volcanic cloud rising from the volcano of Pichincha and towering over Quito the capital city of Ecuador. The picture has considerable resonance for me because I once walked over that mountain with John Baldock and his two sons, aged 8 and 10 at the time. The volcano was completely dormant and had been for many years. For us it was rather like walking over a Scottish moorland on a fine spring day. There could be no greater contrast than my personal experience of Pichincha and that shown on the cover of the book. The picture is so powerful that it is surprising to find that there is no mention of that volcano in the written section of the book. There is, however, a short descriptive paragraph on the back cover. The book, published by the Cambridge University Press, is a multiauthor production resulting from the perception by Marti and Ernst of the need for a comprehensive, authoritative examination of the great variety of volcanic phenomena within a single volume. It is the result of the realisation by the authors that there was no single modern text which dealt with the impact of vulcanicity on the natural world.

The title indicates that volcanoes do indeed have a significant impact on the natural and built environment. Most people probably consider this to relate mainly to the biological environment and those aspects of the physical environment which contribute to the biological environment. Nevertheless, the activities and the artefacts of our species do impinge on the natural environment to an increasingly greater degree, most notably perhaps in the development of modern cities and the extended web of their infrastructure, the construction of roads, railways and other kinds of communication networks. These factors ensure that mankind and the artefacts of our species are increasingly vulnerable to the more violent aspects of the natural world, represented most spectacularly by the eruptions of volcanoes.

There is a short discussion on the question of vulcanicity on other planets in the solar system and of our own moon and it would seem that there is no good evidence for plate tectonic activity on any of them. It is suggested that vulcanicity on the moon stopped as recently as several tens of million years ago. Our own planet Earth may be the only body in the system which is characterised by lateral crustal movements of extensional and collisional character.

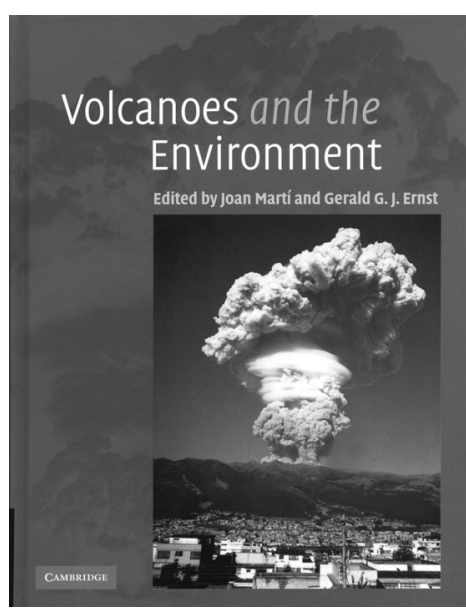

Ages of 4,400 Ma have been obtained from detrital zircons in quartzite from West Australia. These are thought to have been derived from a granite which is no longer exposed. There must therefore have been a solid crust of that age, prior to the formation of the oldest known crustal rocks. Other examples of ancient crustal rocks are the Issua Greenstone Belt in Greenland 3,800 Ma, and the Acasta Tonalite, in Slave Province of Canada 3,962 Ma.

The fairly recent recognition of sea floor spreading and the recognition of the present day Plate Tectonic system provides a model which can be applied to earlier geological situations with a reasonable expectation of some concordance. It also provides criteria which enable the distinction of some ancient geological regimes from those of the present time. The role of vulcanicity during geological cycles is profound in creating complex interactions between lithospere, atmosphere, hydrosphere and biosphere. We should not forget, however, that the essential features of Plate Tectonics were formerly recognised by Holmes (1944) and the movement of the continents (Continental Drift) by Wegener (1924) and Du Toit 1937.

The book consists of fifteen chapters, each describing a different aspect of the nature of vulcanicity ranging from the volcanoes themselves to the multifarious aspects of their activity in the internal and external economy of the planet ranging from volcanoes and the geological cycle (Chapter 4) to mass extinctions (Chapter 7). The variety and scope of the topics addressed are best indicated by listing the chapter headings:

1. Understanding the physical behaviour of volcanoes.

2. Volcano hazards.

3. Anticipating volcanic eruptions.

4. Volcanoes and the geological cycle.

5. Effects of volcanic eruptions on atmosphere and climate.

6. Volcanoes, hydrothermal venting and the origin of life.

7. Volcanoes and mass extintions.

8. Effects of modern volcanic eruptions on vegetation.
9. Animals and volcanoes: survival and revival.

10.Human impacts on volcanoes.

11. Volcanoes, geothermal energy, and the environment.

12. Volcano-hosted ore deposits.

13.Industrial uses of volcanic materials.

14. Volcanoes, society, and culture.

15 . Volcanoes and the economy.

The first chapter by Stephen Carey sets the global scene by showing the distribution of present day volcanic activity within the framework of plate tectonics with vulcanicity concentrated in linear belts of spreading at mid ocean ridges and subduction at continental margins. Although it is the latter which provides the bulk of the visible vulcanicity and virtually everything which affects humanity, it is clear that the driving force for the system is that of the mid ocean ridges and ocean floor spreading.

I was brought up to believe that organic life began during early Cambrian times. However, K. O. Stetter shows in Chapter 6 that bacteria and stromatoliths were already present 3.5 billion years ago and life may have emerged considerably before that time.

Although I have mapped considerable areas of volcanic rocks in various parts of our globe, I have never been involved in a close study of any modern volcano. As a result my knowledge of present day volcanoes is completely superficial. It has, however, been considerably broadened as a result of reading and commenting on this volume, which can be recommended for all geologists who are likely to stumble across volcanic rocks of any age.

\section{References}

Holmes A., 1944, Principles of Physical Geology. Thomas Nelson \& Sons LTD, 532p.

Wegener A., 1924, The Origin of Continents and Oceans. Methuen. London, 248p.

Du Toit A. L., 1937, Our Wandering Continents. Oliver \& Boyd, Edinburgh, 366p.

\section{Dr. John Cobbing}

25 Main Road

Radcliff On Trent

Nottingham NG 12 2BE

$U K$

j.cobbing@bluecom.net 


\section{The evolution of clastic sedimentology}

\section{By Hakuyu Okada with Alec J. Kenyon-Smith}

Dunedin Academic Press Ltd, Edinburgh, 2005, xix + 251 pp., Hardback. $£ 50.00$, ISBN 1903765498.

This valuable book was first published in Japanese in 2002, under the title Sedimentology: a way to the new discipline of earth sciences. Given the problems that nearly all non-Japanese people have in reading Japanese, its translation into English in an expanded form, accomplished with the help of Professor Kenyon-Smith, is exceedingly welcome, given that it is the first book to provide a history of sedimentology. I should say at the outset that the translation is firstrate, being a model of clarity that puts many modern English-language texts to shame. The book is also copiously illustrated, including many photo-portraits of persons previously only known to me by name or through their writings.

Professor Okada is a retired academic sedimentologist, but it is immediately apparent from his text that he has, through much of his career, given close attention to the history and development of his discipline, and has himself participated in that development to a considerable degree. $\mathrm{He}$ shows particular interest in the emergence in the 1950/60s of the discipline as a recognized branch of the earth sciences (so that one might describe oneself today as a sedimentologist, rather than a geologist). The term 'sedimentology' was, I learned, coined by A. C. Trowbridge in the 1920 s, but it did not immediately catch on, partly for the pedantic objection, raised by W. H. Twenhofel, that the term had both Latin and Greek roots (sedimentum and logos)! It was the Dutchman D. J. Doeglas who was most prominent in getting acceptance for the 'new science' and through his efforts, and others', various institutions and journals were established in the 1960s, giving institutional expression to the existence of sedimentology. (Incidentally, The Netherlands, a land of flat sediments and muds, has long been a breeding ground for sedimentologists!)

But while the discipline of sedimentology was established in the post-War period (and Okada devotes considerable attention to this issue) there were obviously many earlier studies that would count as sedimentology if the term had then existed. Okada's bibliography prompted me to read a paper by H. C. Sorby (1908), which described his measurement of the size and shape of ripple marks, from which he was able to make plausible estimates of the rates of rippledrift, a topic on which he had been working

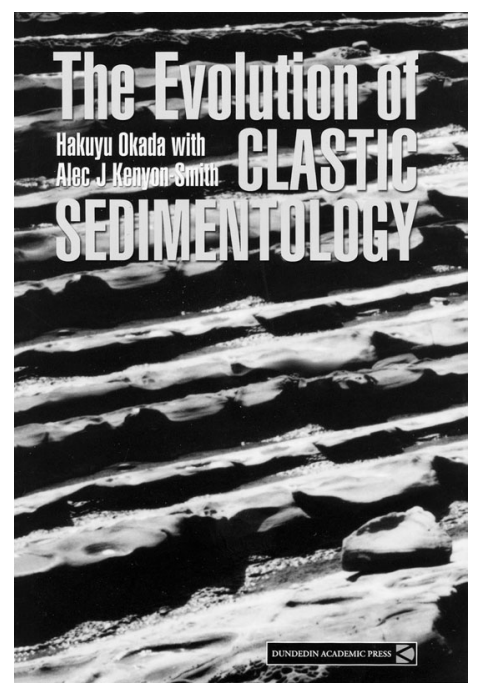

since the 1850s. Sedimentology obviously existed as a practice well in advance of the name.

The book begins, then, with a characterization of what is meant by the term sedimentology. Chapter 2 sketches some wellknown features of the early history of geology, especially in regard to map-making, stratigraphy, uniformitarianism, and geosyncline theory. Chapter 3 (entitled 'Development of the observation of strata') deals with sedimentary processes, the analysis of palaeoenvironments, palaeocurrent analysis, basin analysis, turbidity currents, seismic stratigraphy, and sequence stratigraphy. Next there comes a chapter on the development of sedimentary petrology and of lithology (including a discussion of the notions of facies and facies analysis). There follows a chapter on the establishment of sedimentology (as previously mentioned), and then one on the study of the sediments of ocean floors. A chapter on the development of sedimentology in Japan could be described as a kind of 'bonus', for although it is a little 'out of sync' with the rest of the book it is most welcome as it discusses issues that will probably be unfamiliar to most readers outside Japan; yet it makes clear what a large amount of work has been done in that country and how great is the interest in the field there. Finally, Professor Okada looks forward to possible developments in sedimentology in the 21 st century, for which difficult act of 'glass-ball gazing' he chiefly considers the contributions that may be made by sedimentologists to the studies of the Moon's surface and those of the planets other than the Earth.

The authors rightly gives close attention to the provision of good, clear definitions of the terms used in his science. Thus the first sentence in the book states forthrightly: "Sedimentology is a discipline of the earth sciences that studies the nature of sediments and sedimentary rocks and the processes of their formation in order to determine the earth's past environments". Naturally, this encompasses the description and classification of sediments, and thus sedimentary petrology also.

More difficult is a satisfactory characterization of the notion of sedimentary facies. Okada helpfully lists the many usages of the term, and chooses to accept the definition of C. Teichert (1958): "[f]acies is the sum total of all primary characteristics of a sedimentary rock, from which the environment of its deposition may be deduced". It is a pity, though, that he uses the term early in the book, whereas the detailed discussion of facies is held over until Chapter 5. A forward cross-reference would have solved this problem.

Chapter 7, 'Sedimentology and the study of the ocean floor', is somewhat more detailed than the other parts of the book, and seems to reflect the author's special research interests. It is an important and somewhat complex chapter, for while it begins with a straightforward historical account of the work of the Challenger expedition in the 1870 s it comes forward to modern considerations of ocean currents (especially bottom currents), the problem of black shale deposits, and possible connections with plate tectonics and plume theory.

The book is very much a work of scientist-historians (as opposed to historians of science). In this regard, some of the text, especially the later chapters, reads rather more like a literature review than history of science, with scrupulous listing of the accomplishments of as many individuals as possible. And it appears very much as a 'success story' - seemingly one that has been largely free of controversies, which are studiously avoided by the authors. For example, one would not know, from this account, how much controversy (especially about the 'Vail Curve') attended athe emergence of sequence stratigraphy, and the locking up of 'commercial in confidence' data for a considerable period by the Exxon research group, so that their results could not be evaluated by others in the normal academic fashion. On the other hand, a good, clear, brief account is given of the main features of sequence stratigraphy, which is historically a complex topic.

A section is devoted to what Okada calls 'social sedimentology', which includes, for example, the contributions made by sedimentologists to the study of the well-known Minamata mercury pollution episode in Japan. Certainly in this case sedimentological expertise was applied to a social problem, but I am not sure that 'social sedimentology' can be regarded as a distinct enterprise. We might, for the time being, call it applied sedimentology. This raises the question of the contributions that sedimentology have made to petroleum geology, e.g., through sequence stratigraphy. Here, I think, a separate chapter might have been warranted-but, as I understand, sequence stratigraphy has not made a huge contribution to oil discoveries, despite the fact that 
petroleum companies were so prominent in the development of that line of work. Here it may be mentioned that there is not a great deal about oil in this book, though there is a fair amount on coal.

In sum, we have a most valuable 'first vintage' - notable for its clarity and precision - for those who want to know about the history of sedimentology. For the most part, its readers are likely to be geologists, and they will find that it provides an excellent guide to the literature in the field. It is much to be hoped that others will follow the lead from the Far East, and explore in greater detail the history of sedimentology, especially for the second half of the 20th century, for which not too much work has yet been done. As an 'insider', Professor Okada has shown us the main outlines of his discipline, and any future historical work on sedimentology will surely be based on this book.

\section{David Oldroyd}

School of History and Philosophy of Science

The University of New South Wales

Sydney, 2052

AUSTRALIA

d.oldroyd@unsw.edu.au

\section{Petroleum geoscience}

\section{By Jon Gluyas and Richard Swarbrick}

\section{Blackwell Publishing, Oxford, 2004, 359 pages, £37.50; US\$85, ISBN 0632037679}

Successful textbooks educate generations, and in a way define generations of scientists. As science and technology advance, textbooks become old and outdated. Nevertheless, each textbook serves as a foundation for the next, and thus a series of textbooks on a particular subject reflects the evolution of concepts, methods and data on the subject. As I write this review, there are eight textbooks on petroleum geology on my bookshelf: D. Hager's Practical Oil Geology (1915) (the first textbook of its kind); W.H. Emmons' Geology of Petroleum (1921), Cecil Lalicker's Principles of Petroleum Geology (1949); William Russell's Principles of Petroleum Geology (1951); Kenneth Landes' Petroleum Geology (1951); A. I. Levorsen's Geology of Petroleum (2nd ed., 1967); F. K. North's Petroleum Geology (1985); and Richard Selley's Elements of Petroleum Geology (2nd ed., 1998). Petroleum Geoscience by Gluyas and Swarbrick is a welcome addi-

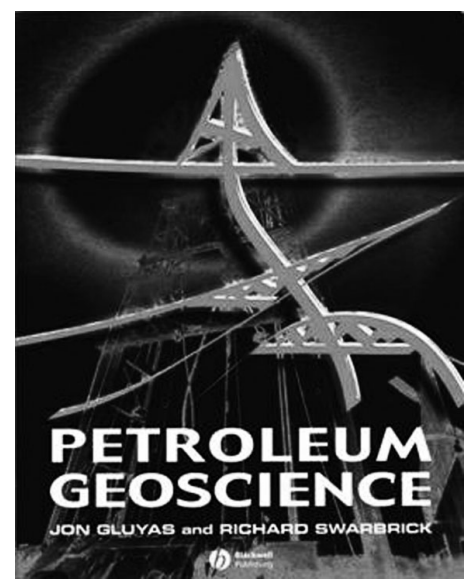

tion to this list although its authors do not mention their predecessors.

What sets this book apart from the previous textbooks is not only the new information it contains, but also a novel presentation style. As the authors note, the book follows a path known as the "value chain" in the petroleum industry. It begins with frontier exploration, proceeds through discovery and leads to production. In this way, the book consists of six lengthy chapters: Introduction (16 pages); Tools (35 pages); Frontier Exploration (64 pages); Exploration and Exploitation (87 pages); Appraisal (68 pages); Development and Production (66 pages). Of course, most of these topics are also found in the previous textbooks, but with new data, examples and illustrations, and the arrangement of topics, teachers will find it a useful tool to help students explore how petroleum geology works. Each chapter ends with at least three case studies, integrating in a particular manner what has been learned in that section. For example, the chapter on exploration and exploitation has case studies from Alaska's North Slope, Viboral basin in eastern Venezuela, and California's San Joaquin basin.

Authors' combination-Gluyas (from industry) and Swarbrick (from academia) results in a balanced book containing both theory and industrial applications. In the preface, the authors tell the story of how the book was written: They met at the 1992 international convention of the American Association of Petroleum Geologists in London, and discussed the necessity for a new textbook on petroleum geoscience. It took twelve years to realize this goal. Writing textbooks can be quite laborious, and their efforts are commendable.

Geoscience includes geology, geochemistry and geophysics. The geochemical aspects of petroleum in this book have received less attention than the other two disciplines. Only two pages are devoted to petroleum chemistry and six pages to petroleum source rocks. Overall, the book focuses on petroleum geology applied to exploration, appraisal, development, and production. A bibliography of more than 360 refer- ences, many of which were published in the 1980 s and 1990s, is a valuable source for further reading. This book is primarily intended for an upper graduate-level course on petroleum geology. Experienced petroleum geologists will also find it useful, refreshing their knowledge and learning about some unpublished data from work done previously at British Petroleum.

Every geologist has his or her favorite textbook on petroleum geology. When I was a geology student, our textbook was Levorsen's. Then I added Selley and North to the list of my favorites. And now this book by Gluya and Swarbrick. I highly recommend it.

\section{Dr. Rasoul Sorkhabi}

Research Professor

Energy \& Geoscience Institute

University of Utah

Salt Lake City, Utah

USA

rsorkhabi@egi.utah.edu 